\title{
Recent progress on oxygen and hydrogen peroxide reduction reactions on Pt single crystal electrodes
}

\author{
Valentín Briega-Martos, Enrique Herrero, Juan M. Feliu *
}

\section{Introduction}

The oxygen reduction reaction (ORR) is probably the most important cathodic process in electrocatalysis because of its universal role as comburent in life and key applications in several fields such as fuel cells, corrosion processes or lithium-air batteries. Despite many experimental and theoretical investigations that have been carried out during the last years and contributed to improve the knowledge about this reaction, the complete mechanism for the ORR is not elucidated yet [1]. The ORR involves the exchange of 4 electrons and 4 protons for the complete reduction of $\mathrm{O}_{2}$ to water (Eq. 1). The reaction mechanism is complex and implies the formation of several intermediates involving $\mathrm{O}=\mathrm{O}$ bond scission and $\mathrm{O}-\mathrm{H}$ bond formation.

$$
\mathrm{O}_{2}+4 \mathrm{H}^{+}+4 \mathrm{e}^{-} \rightleftharpoons 2 \mathrm{H}_{2} \mathrm{O} E_{1} 0=1.229 \mathrm{~V} \text { vs. SHE }
$$

It was demonstrated that $\mathrm{H}_{2} \mathrm{O}_{2}$ is a reaction intermediate for this reaction under certain conditions [2-4]. $\mathrm{H}_{2} \mathrm{O}_{2}$ could be the final product in a 2-electron reduction process (Eq. 2), or it could be further reduced to water (Eq. 3).

$$
\mathrm{O}_{2}+2 \mathrm{H}^{+}+2 \mathrm{e}^{-} \rightleftharpoons \mathrm{H}_{2} \mathrm{O}_{2} \quad E_{2}{ }^{0}=0.695 \mathrm{~V} \text { vs. SHE }
$$

$\mathrm{H}_{2} \mathrm{O}_{2}+2 \mathrm{H}^{+}+2 \mathrm{e}^{-} \rightleftharpoons 2 \mathrm{H}_{2} \mathrm{O} E_{3} 0=1.776 \mathrm{~V}$ vs. SHE (3)

The study of the hydrogen peroxide reduction and oxidation reactions (HPRR and HPOR) is therefore crucial for a better understanding of the ORR as it is a possible stable intermediate.

Previous theoretical studies taking into account the binding energy of $\mathrm{OH}$ intermediate indicated that $\mathrm{Pt}(111)$ is the most active surface towards the ORR [5]. However, the analysis of the electrocatalyitic activity of the basal planes by extrapolation of experimental data for stepped surfaces pointed out that the stepped surfaces are more active than $\mathrm{Pt}(111)$ in acidic media [6-8], while in alkaline media experimental results and theory agree better [9]. This has been a controversial point during all the ORR research. The surface charge of the electrode can also have an influence towards the kinetics of the electrocatalytic reactions, but its specific effect has not been considered until recent works. The study of the ORR in different surface charge conditions can help to overcome the unsolved aspects for this reaction.

Other problems to elucidate the ORR mechanism are the dif- ficulty for identifying the reaction intermediates. The traditionally available techniques are not able to detect all the reaction intermediates in the ORR [10]. Because of that it is important to compare theoretical calculations with the available experimental results in order to propose the possible intermediates $[11,12]$.

In this perspective paper, the most recent advances in the understanding of the ORR (and the HPRR) on well-oriented Pt surfaces are summarized in order to provide a general vision of what is known to date and the next strategies that could be employed.

\section{Effect of the surface charge on the ORR and the HPRR}

The adsorption energy of the ORR intermediates is usually the descriptor used in kinetic investigations [5]. However, the electrode surface charge can also have a markedly influence on the electrocatalytic reactions [13]. For the study of the effect of the surface charge on the electrocatalytic activity of Pt electrodes is necessary to use working solutions without the presence of anions that adsorb specifically, since the latter ones can also modify the reactivity of the electrode [7]. The use of $\mathrm{NaF} / \mathrm{HClO}_{4}$ mixtures resulted to be suitable for this type of study at different $\mathrm{pH}$ because the $\mathrm{p} K_{\mathrm{a}}$ of hydrofluoric acid is ca. 3 and $\mathrm{F}^{-}$does not adsorb specifically on Pt [14]. This kind of electrolyte was used to study the ORR on Pt basal planes and different stepped surfaces in a pH range up to until 5.6 [15]. The cyclic voltammetry results for $\mathrm{Pt}(111)$ show that the onset potential moves to slightly more positive values as the solution pH increases (Figure 1A). The kinetic current densities at 0.85 $\mathrm{V}$ vs. RHE obtained by using the Koutecky-Levich equation are also improved as the $\mathrm{pH}$ is changed from acid to more neutral values (Figure 1D). The reaction was also studied in alkaline $\mathrm{pH}$ values from $\mathrm{pH} 11.9$ to 13.1 using $\mathrm{NaOH} / \mathrm{KClO}_{4}$ mixtures, and in this case the higher the $\mathrm{pH}$, the lower the kinetic current densities (Figure 1D). In conclusion, for Pt(111), the plot $j_{\text {kin }}$ vs. $\mathrm{pH}$ shows a volcano trend with the maximum centered at $\mathrm{pH}$ ca. 9. The proposed explanation for this behavior was based on the fact that the potential of zero free charge (pzfc) for $\operatorname{Pt}(111)$ 

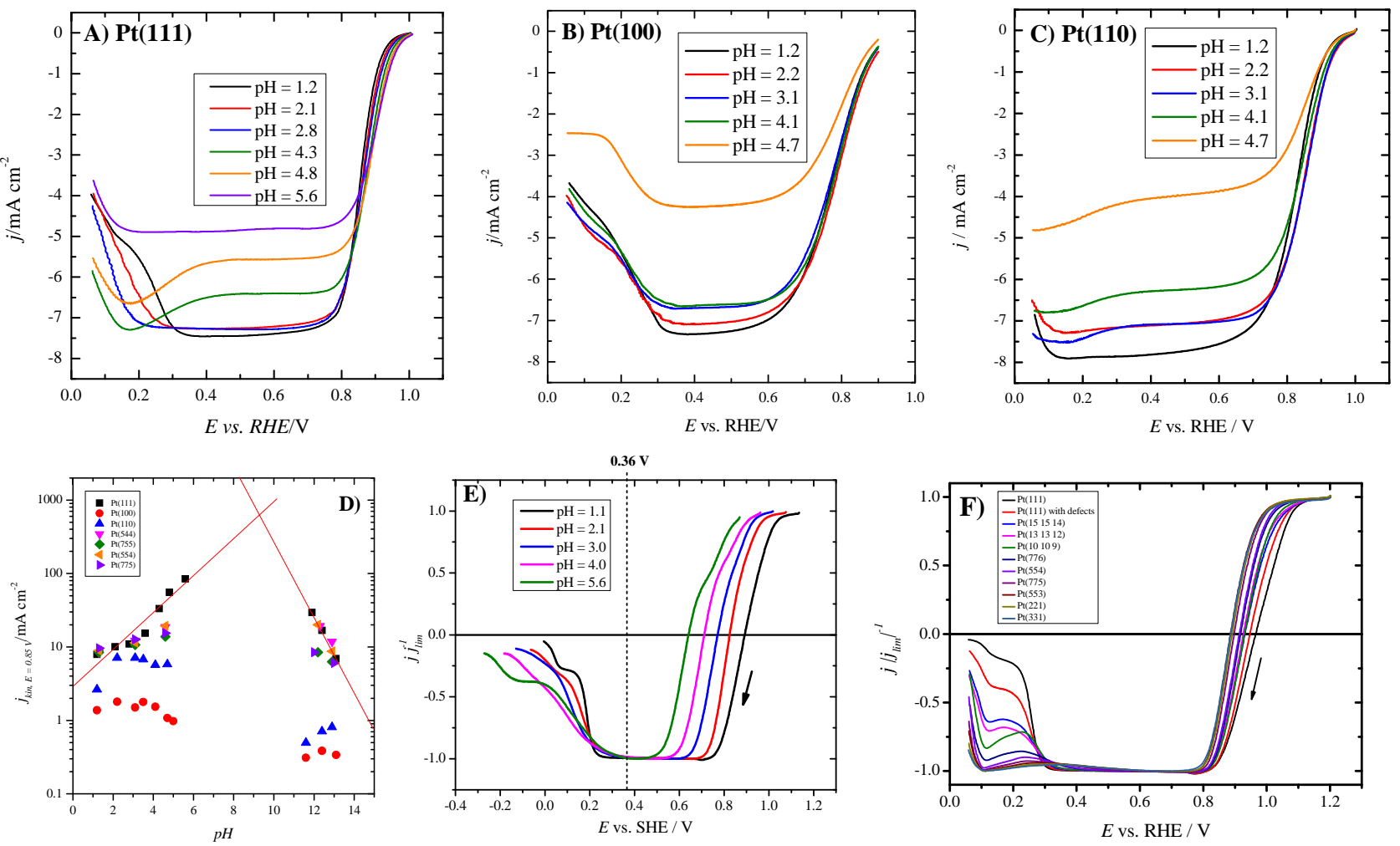

Fig. 1. Polarization curves for the ORR on $\mathrm{Pt}(111)(\mathrm{A}), \mathrm{Pt}(100)(\mathrm{B})$ and $\mathrm{Pt}(110)(\mathrm{C})$ in $\mathrm{O}_{2}$-saturated solutions with pH < 5.6 prepared with $\mathrm{NaF} / \mathrm{HClO} 4$ mixtures. Plot of the logarithm of $j_{\mathrm{k}}$ at $0.85 \mathrm{~V}$ on the different Pt single crystal electrodes as a function of $\mathrm{pH}$. The straight lines correspond to Pt(111) (D). Normalized polarization curves for the HPRR and HPOR on $\mathrm{Pt}(111)$ in $1.7 \mathrm{mmol} / \mathrm{L} \mathrm{H}_{2} \mathrm{O}_{2}$ with $\mathrm{pH}<5.4 \mathrm{prepared} \mathrm{with} \mathrm{NaF} / \mathrm{HClO}{ }_{4} \mathrm{mixtures}$ in the SHE scale. The dotted line marks the potential at which the first current drops starts for the different $\mathrm{pH}$ values (E). Normalized polarization curves for the HPRR and HPOR on different $\mathrm{Pt}(\mathrm{S})[\mathrm{n}(111) \times(111)]$ stepped surfaces in $0.1 \mathrm{~mol} / \mathrm{L} \mathrm{HClO}_{4}$ and $1.7 \mathrm{mmol} / \mathrm{L} \mathrm{H} \mathrm{H}_{2}(\mathrm{~F})$. Scan rate: $50 \mathrm{mV} / \mathrm{s}$; rotation rate: $2500 \mathrm{rpm}$ (for all the figures). Figures 1A, 1B, 1C, and 1D are adapted from Ref. [15]. Figure 1E is adapted from Ref. [16].

moves to more positive potentials in the RHE scale as the $\mathrm{pH}$ is increase from acidic values to $\mathrm{pH}=6$. Therefore, the onset potential for the ORR is closer to the pzfc for neutral $\mathrm{pH}$ values. The electrocatalytic activity would be maximum when the onset potential is close to the pzfc for the Pt(111) surface. When the $\mathrm{pH}$ is increased to alkaline values, the onset potential is gradually more negative than the pzfc, and thus the electrocatalytic activity decreases again. For Pt(100) and Pt(110) the situation is different (Figures $1 \mathrm{~B}$ and $1 \mathrm{C}$ ): the $j_{\mathrm{k}}$ values decreases slightly as the $\mathrm{pH}$ is increased in the whole potential range. This is because for $\mathrm{Pt}(111)$ the onset potential lies at potential values where $\mathrm{OH}$ species are adsorbed, but as the potential is swept to more positive values adsorbed $\mathrm{OH}$ desorbs at ca. 0.7. In the case of the other basal planes, however, the $\mathrm{OH}$ desorption takes place at much more negative values, and therefore at the relevant potential region for the ORR the surface always is covered by $\mathrm{OH}$. The ORR is then mainly affected by the adsorbed $\mathrm{OH}$ and this is the reason for the almost constant observed behavior. The situation for the $\operatorname{Pt}(S)[(n-1)(111) \times(110)]$ and $\operatorname{Pt}(S)[n(111) \times(100)]$ is intermediate, since it can also be observed a volcano trend but with less pronounced slopes. This is because the fraction of (111) terraces is smaller as the step density is increased and may suggest that the overall reactivity depends on local contributions from terraces and steps. The possible effects of the surface charge on the ORR mechanism are discussed in Sections 4 and
5.

The effect of surface charge was also studied for the HPRR [16]. The inhibition of the current density that takes place at low potentials for the ORR on Pt(111) was traditionally ascribed to the adsorption of hydrogen, which would hinder the scission of the $\mathrm{O}-\mathrm{O}$ and yielding thus $\mathrm{H}_{2} \mathrm{O}_{2}$ instead of water [3]. However, measurements with $\mathrm{NaF} / \mathrm{HClO}_{4}$ mixtures at different $\mathrm{pH}$ values showed that this inhibition always occurs at the same potential in the SHE scale (Figure 1E) [16]. This potential is very near to the potential of maximum entropy (pme) for $\mathrm{Pt}(111)$. Consequently, the inhibition must be related to some change in the interfacial water or to the surface charge of the electrode instead of the proposed hydrogen adsorption. The HPRR was also studied in alkaline media, but in this case the inhibition potential is determined by the $\mathrm{OH}$ adsorption/desorption potential [16].

Further studies have been carried out using Pt stepped surfaces (Figure 1F). On one hand, it can be observed that the current density inhibition potential shifts to more positive potential values with step density. This is in agreement with the variation of the local pme for terraces in stepped surfaces measured by laser-induced temperature jump experiments [17]. On the other hand, the intensity for the current density minimum observed at ca. $0.11 \mathrm{~V}$ vs. RHE increases as the step density is increased and this potential coincides well with the local pme for steps. In conclusion, there is a clear influence of the local 
surface charge properties towards the HPRR.

\section{Experimental evidences of a bifurcation point in the ORR mechanism}

Since the mechanism for the ORR involves several steps, there can exist bifurcation points from which, depending on the conditions, the reaction can follow different pathways. The $\mathrm{OOH}^{\bullet}$ species has been proposed previously in several works as a possible bifurcation point which could yield directly adsorbed $\mathrm{O}$ and $\mathrm{OH}$ or produce $\mathrm{H}_{2} \mathrm{O}_{2}$ [10]. It can be seen in Figure $1 \mathrm{~A}$ that the limiting current densities for the ORR on Pt(111) decreases as the solution $\mathrm{pH}$ is increased from $\mathrm{pH}$ ca. 3 . Analogous experiments for HPRR with a $\mathrm{H}_{2} \mathrm{O}_{2}$ concentration that would lead to the same limiting current densities were performed, but in this case no decrease of $j$ lim was observed (Figure 2A) [15]. It was proposed that this behavior for the ORR is due to the existence of a bifurcation point before the formation of $\mathrm{H}_{2} \mathrm{O}_{2}$. This previous intermediate would stop reacting electrochemically giving rise to a reduction in the faradaic efficiency. This intermediate was suggested to be $\mathrm{OOH}^{\bullet}$ soluble species in light of the results by Gómez-Marín et al. [15].

The mechanism of the ORR was also studied by investigating the effect of the presence of $\mathrm{Br}$ - in working solutions with different $\mathrm{pH}$ values [18]. It was observed that at very acidic $\mathrm{pH}$ values (below $\mathrm{pH}=1$ ) the presence of $\mathrm{Br}^{-}$reduces the $j_{\text {lim }}$ to the half of its theoretical value. Therefore, the final product in these conditions is $\mathrm{H}_{2} \mathrm{O}_{2}$. However, as solution $\mathrm{pH}$ increases, the $j_{\mathrm{lim}}$ diminution is less drastic, and from $\mathrm{pH}=3$ the same $j_{\text {lim }}$ values as those measured in absence of $\mathrm{Br}^{-}$are obtained. Furthermore, the onset potential in the presence of $\mathrm{Br}^{-}$shifts to more positive potential values as $\mathrm{pH}$ increases. Additionally, measurements for the HPRR in the same conditions were carried out (Figure 2B) [18]. In all cases the $j_{\text {lim }}$ measured for the ORR is higher than the sum of the theoretical $j$ lim for a 2-electron process and the measured current for the HPRR. This difference is especial-
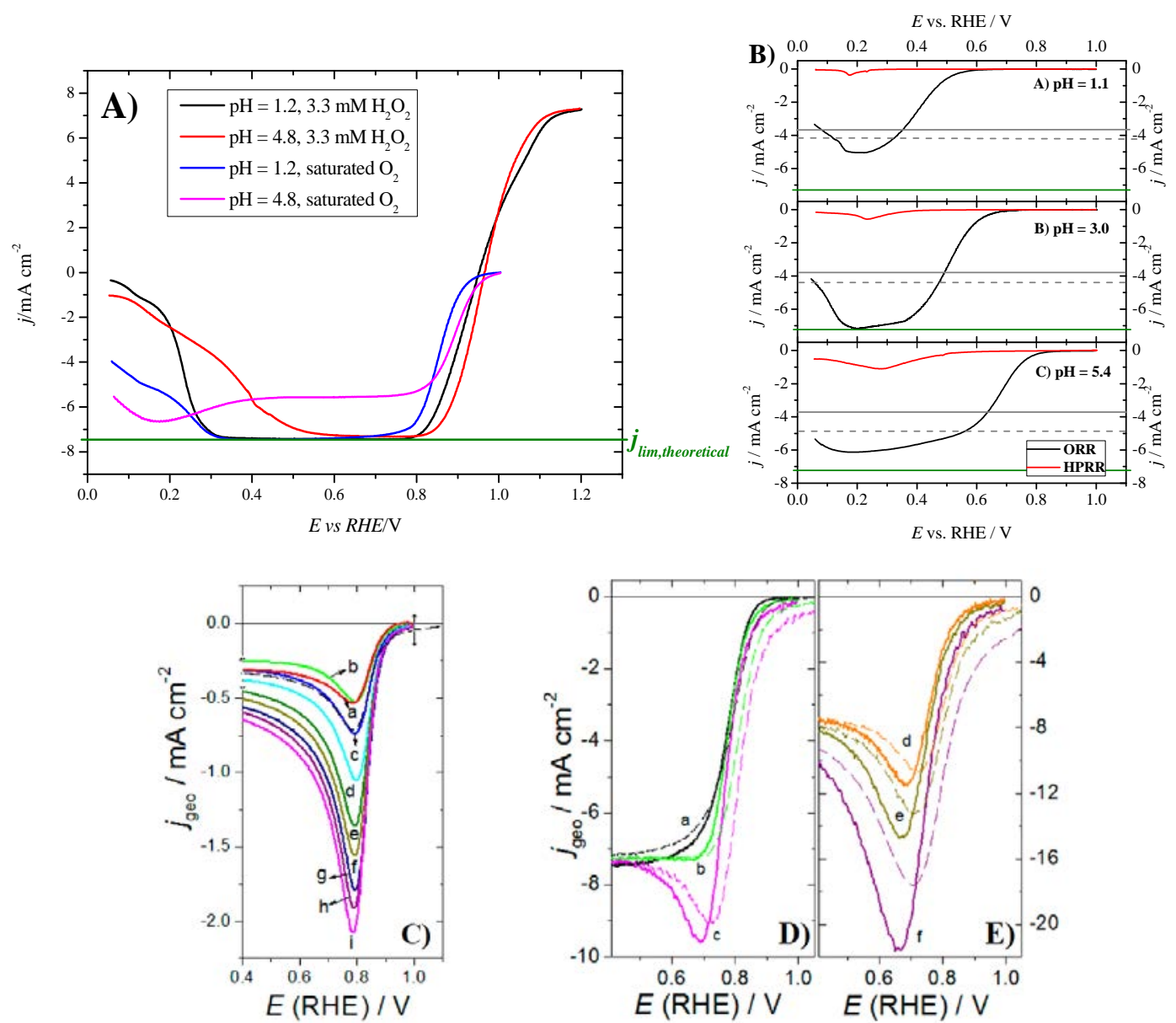

Fig. 2. Comparison between the ORR and the HPRR/HPOR at different pH values for the same limiting current density. The green line represents the

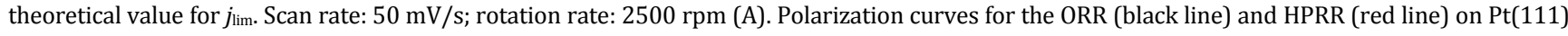
in the presence of $10^{-2} \mathrm{~mol} / \mathrm{L} \mathrm{KBr}$ in the indicated $\mathrm{pH}$ values. Scan rate: $50 \mathrm{mV} / \mathrm{s}$; rotation rate: $2500 \mathrm{rpm}$. Grey line represents half (2e-) of the theoretical $j_{\text {lim }}$ for the ORR $\left(4 \mathrm{e}^{-}\right)$and the grey dashed line indicates the addition to this value of the experimental $j$ lim obtained for the HPRR. The green line represents theoretical $j_{\text {lim }}$ for the ORR (B). Linear sweep voltammograms for the oxygen reduction in $\mathrm{O}_{2}$-saturated 0.1 mol/L $\mathrm{HClO}_{4}$ on stationary Pt(poly) electrodes after conditioning and holding at $E_{i}=1.02 \mathrm{~V}$ (OCP) for different resting times $\tau_{h}$ of (a) 0, (b) 1, (c) 5, (d) 15, (e) 30, (f) 45, (g) 60, (h) 90, and (i) $120 \mathrm{~s}$ and steady-state cycle for the continuous LSV (dashed line). Scan rate: $0.1 \mathrm{~V} / \mathrm{s}$ (C). Linear sweep voltammograms for the ORR at $\mathrm{Pt}$ (Poly) in $\mathrm{O}_{2}$-saturated $0.1 \mathrm{~mol} / \mathrm{L} \mathrm{HClO}_{4}$ on RDEs at $2500 \mathrm{rpm}$ after conditioning and holding the potential at $E_{i}=0 \mathrm{OCP}$ a resting time $\tau_{h}=150 \mathrm{~s}$. The scan rate is (a) 0.1 , (b) 0.8, (c) 2 (D), and (d) 3, (e) 5, (f) $10 \mathrm{~V} \mathrm{~s}^{-1}$ (E). For the sake of comparison steady-state cycles for continuous LSVs (dashed) are also given. Figures $2 \mathrm{~A}$ and 2B are adapted from [18]. Figures 2C, 2D, and 2E are adapted from Ref. [19]. 
ly important for $\mathrm{pH}=3$, where the $j_{\text {lim }}$ for the ORR agrees well with the theoretical value (green line in Figure 2B) while the HPRR is markedly inhibited. It is important to remark that the difference between the measured $j_{\text {lim }}$ for the ORR and its theoretical value in Figure 2B for $\mathrm{pH}=1.1$ is due to the presence of $\mathrm{Br}^{-}$, while the difference in the case of $\mathrm{pH}=5.4$ is due to the solution $\mathrm{pH}$ and $j_{\text {lim }}$ is the same in the presence and in the absence of $\mathrm{Br}^{-}$(see Ref. [18]). All these results indicate that the mechanism for the ORR does not follow a sequential scheme in which $\mathrm{H}_{2} \mathrm{O}_{2}$ is generated as an intermediate. There must be a bifurcation point that follows a pathway for producing water without the formation of $\mathrm{H}_{2} \mathrm{O}_{2}$. This intermediate was also proposed to be $\mathrm{OOH}^{\bullet}$ species [18].

Gómez-Marín et al. [19] also observed evidences of $\mathrm{OOH}^{\bullet}$ intermediate by carrying out experiments under non-steady-state conditions for polycrystalline Pt. Linear sweep voltammetry (LSV) experiments in static conditions after holding the potential at $1.02 \mathrm{~V}$ vs. RHE during different resting times pointed out that the peak current density $\left(j_{\mathrm{p}}\right)$ is higher for the longest resting times (Figure 2C). In addition, measurements at different scan rates for the same resting time were also performed, and in all cases $j_{\mathrm{p}}$ is higher after holding the potential at the open circuit value during $150 \mathrm{~s}$ than the $j_{\mathrm{p}}$ value for the continuous LSV in steady state (Figure 2D). The authors suggested that $\mathrm{OOH}^{\bullet}$ soluble species are formed in a fast initial chemical reaction, and equilibrium is reached in such a way that no currents are measured at potentials higher than the onset potential. Once the onset potential is attained, this intermediate species would be reduced yielding the next reaction intermediates [19].

\section{Spectroelectrochemical and computational methods for intermediates identification}

As mentioned in the Introduction section, one of the most difficult challenges during the investigation of the ORR is the detection and identification of the reaction intermediates. The use of spectroelectrochemical methods together with theoretical studies is a common tool for determining these intermediates [11], but in the case of the ORR the detection limits of these techniques are usually too high. However, a recent study using the shell-isolated nanoparticle-enhanced Raman spectroscopy (SHINERS) with the Pt basal planes electrodes in acid and alkaline media proves the identification of ORR intermediates. This spectroelectrochemical technique consists on modifying the $\mathrm{Pt}$ surface with gold nanoparticles coated by an ultrathin and uniform silica shell. These nanoparticles are able to strongly enhance the Raman signal of molecules situated near the nanoparticle surface. By using this enhancing strategy the detection limits are suitable for the detection of ORR intermediates.

Figure 3A shows the SHINERS spectra at different potential values for $\mathrm{Pt}(111)$ in $0.1 \mathrm{~mol} / \mathrm{L} \mathrm{HClO}_{4} \mathrm{O}_{2}$-saturated solutions. It can be seen that a band at $732 \mathrm{~cm}^{-1}$ appears from $0.8 \mathrm{~V}$ vs. RHE when potential diminishes. The evolution of the band with the
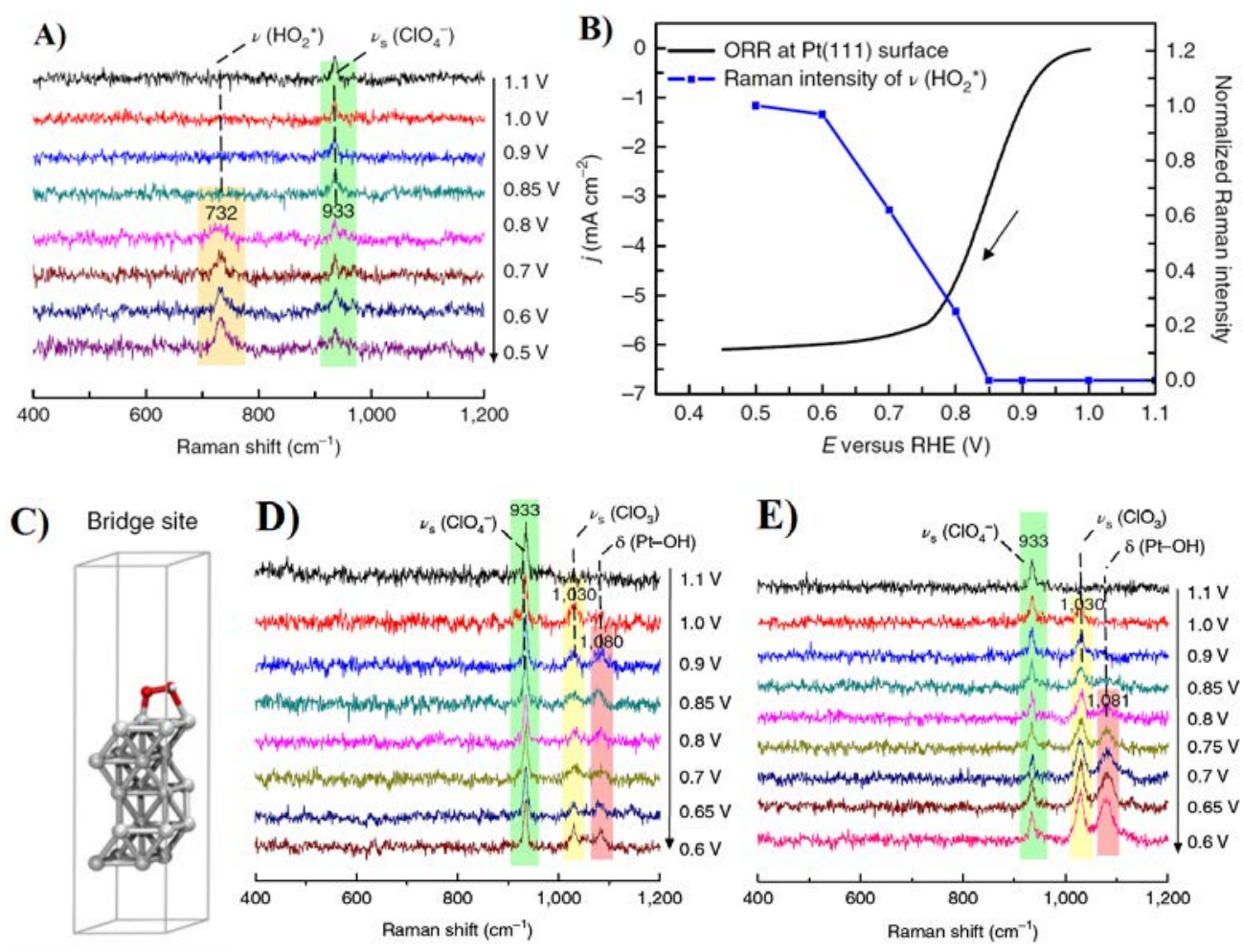

Fig. 3. EC-SHINERS spectra of the ORR system at a $\mathrm{Pt}(111)$ electrode surface in a 0.1 mol/L $\mathrm{HClO}_{4}$ solution saturated with $\mathrm{O}_{2}(\mathrm{~A})$. Normalized EC-SHINERS intensities of the stretching mode of $0-0 \mathrm{H}$ around $732 \mathrm{~cm}^{-1}$ at different potentials and polarization curve of the ORR process at the $\mathrm{Pt}(111)$ surface in a $0.1 \mathrm{~mol} / \mathrm{L} \mathrm{HClO}_{4}$ solution saturated with $\mathrm{O}_{2}$. Scan rate: $50 \mathrm{mV} / \mathrm{s}$; rotation rate: $1600 \mathrm{rpm}$ (B). The arrows in both figures A and $\mathrm{B}$ represent the potential scanning direction and all potentials are relative to the RHE. Side-view illustrations of $\mathrm{OOH}^{\bullet}$ at a stable configuration at a $\mathrm{Pt}(111)$ surface on bridge site adsorption structure (C). EC-SHINERS spectra of the ORR system at Pt(100) (D) and Pt(110) (E) electrodes surface in a $0.1 \mathrm{~mol} / \mathrm{L} \mathrm{HClO}_{4}$ solution saturated with $\mathrm{O}_{2}$. Adapted from Ref. [12]. 
electrode potential and its comparison with the voltammetric results are shown in Figure 3B. The frequency for the $0-0$ stretching vibration for $\mathrm{OOH}^{\bullet}$ species in the bridge configuration on Pt(111) (Figure 3C) was calculated by density functional theory (DFT) and the obtained result was $726 \mathrm{~cm}^{-1}$. This value agrees well with the observed band for the SHINERS spectra, and therefore it was proposed that $\mathrm{OOH}^{\bullet}$ is a reaction intermediate for the ORR on $\mathrm{Pt}(111)$. This is the first case of an experimental evidence for the existence of $\mathrm{OOH}^{\bullet}$ intermediate. Analogous measurements were carried out for $\operatorname{Pt}(100)$ and $\operatorname{Pt}(110)$, and in these cases no band at ca. $730 \mathrm{~cm}^{-1}$ was observed (Figures 3D and 3E). Therefore, $\mathrm{OOH}^{\bullet}$ would be an intermediate only for Pt(111). Instead, a band at ca. $1080 \mathrm{~cm}^{-1}$ was observed for both electrodes (Figures 3D and 3E). By comparison with the DFT calculations results these bands were attributed to $\mathrm{Pt}-\mathrm{OH}$ bending mode. In light of these results, they proposed a mechanism in which $\mathrm{O}_{2}$ forms $\mathrm{OOH}^{\bullet}$ by a proton and an electron transfer. The dissociation energy for this intermediate to form adsorbed $\mathrm{O}$ and $\mathrm{OH}$ is $1.61 \mathrm{eV}$ on $\mathrm{Pt}(111)$, while on Pt(100) this dissociation energy is $0.51 \mathrm{eV}$ (no dissociation energy data is provided for $\operatorname{Pt}(110)$ but it is stated that it is also unstable in comparison with $\mathrm{Pt}(111)$ [12]). Therefore, $\mathrm{OOH}^{\bullet}$ intermediate would be more stable and would need a higher activation energy for dissociating into $\mathrm{O}$ and $\mathrm{OH}$ on $\operatorname{Pt}(111)$ than on $\operatorname{Pt}(100)$ or $\operatorname{Pt}(110)$. This is in agreement with previous theoretical works [20]. Therefore, it is possible to detect it on $\operatorname{Pt}(111)$ while in $\operatorname{Pt}(100)$ and $\operatorname{Pt}(110)$ the $0-0$ breaks quickly making more difficult its observation. These differences between Pt(111) and the other basal planes could also be related with the specific effect of the surface charge. It has been pointed out in section 2 that a different electrocatalytic behavior with $\mathrm{pH}$ is observed for $\mathrm{Pt}(111)$ due to the fixed pzfc from acid to neutral pH values and the more labile adsorbed $\mathrm{OH}$ layer. This could also determine the fact that $\mathrm{OOH}^{*}$ in $\operatorname{Pt}(111)$ is more stable than in $\operatorname{Pt}(100)$ and $\operatorname{Pt}(110)$. Additional measurements in alkaline media $(\mathrm{pH}=10)$ were performed and the superoxide species $\left(\mathrm{O}_{2}^{-}\right)$was detected for the three basal planes.

The adsorption behavior of oxygen and the reaction intermediates for the ORR has been extensively studied by theoretical calculations during the last years. The adsorption and dissociation processes of ORR intermediates on the three basal planes have been discussed recently in the work by Dong et al. [12]. DFT results point out that the bridge configuration is the most stable adsorption mode for $\mathrm{OOH}^{\bullet}$ intermediate on $\mathrm{Pt}(111)$ (Figure 3C). As mentioned above, $\mathrm{OOH}^{\bullet}$ intermediate is less stable on $\mathrm{Pt}(110)$ and $\mathrm{Pt}(100)$. In the case of adsorbed $\mathrm{O}$ and $\mathrm{OH}$ intermediates on $\mathrm{Pt}(100)$ and $\mathrm{Pt}(110)$, it was proposed that $\mathrm{OH}$ species are adsorbed on top and the adsorbed $\mathrm{O}$ atom on the nearest neighbor contributes bending the $\mathrm{H}$ atom. The bridge adsorption mode was calculated to be more stable, but the frequency did not correspond with the experimental value measured by EC-SHINERS. Calculations for $\mathrm{H}_{2} \mathrm{O}_{2}$ showed that a pathway through the formation of this intermediate would be hindered [20]. However, theoretical calculations may not take into account factors such as the surface charge or the surroundings which could alter the formed intermediates, as dis- cussed in the next section.

\section{ORR mechanism according to the recent results}

In light of the previously described studies, the mechanism in Figure 4 is proposed. First, the initial chemical step can take at potential values more positive than the onset potential to form the soluble $\mathrm{OOH}^{\bullet}$ species. Once the onset potential is reached the $\mathrm{O}_{2}$ molecule can be reduced also to the $\mathrm{OOH}^{\bullet}$ intermediate. There is an effect of the surface structure in the ORR mechanism: the $\mathrm{OOH}^{\bullet}$ intermediate is more stable in $\mathrm{Pt}(111)$ and therefore it can be detected by the EC-SHINERS technique, while in $\operatorname{Pt}(100)$ and $\operatorname{Pt}(110)$ its lifetime is smaller and cannot be detected. This could be due to the different adsorption energy of the intermediates on the basal plane orientations or to the effects of the surface charge. As has been already pointed out, surface charge has an effect on the electrocatalytic activity, and therefore it can affect the mechanism. However, at more neutral $\mathrm{pH}$ the decrease on $j_{\text {lim }}$ can also be observed on $\operatorname{Pt}(100)$ and $\operatorname{Pt}(110)$, and this suggests that $\mathrm{OOH}^{\cdot}$ intermediate could be more stable on the latter surfaces in these conditions. On the other hand, the results from the ORR measurements in the presence of bromides suggested that in very acidic solutions the path in which $\mathrm{OOH}^{\bullet}$ is reduced to $\mathrm{H}_{2} \mathrm{O}_{2}$ is preferred, while for more neutral $\mathrm{pH}$ values the mechanism follows a pathway in which $\mathrm{H}_{2} \mathrm{O}_{2}$ would not be formed. For solutions with low ionic strength, the $\mathrm{H}_{2} \mathrm{O}_{2}$ pathway is also favored. When $\mathrm{Br}^{-}$anions are present in the solution, the reduction of $\mathrm{H}_{2} \mathrm{O}_{2}$ is hindered, and therefore the latter is the final product of the reaction. Lastly, when the solution $\mathrm{pH}$ is increased towards more neutral values, the reduction of the $\mathrm{OOH}^{\bullet}$ intermediate is hindered, and it goes to the bulk solution giving thus a decrease in the faradaic efficiency.

\section{Perspectives and conclusions}

In this report the most recent advances for improving the

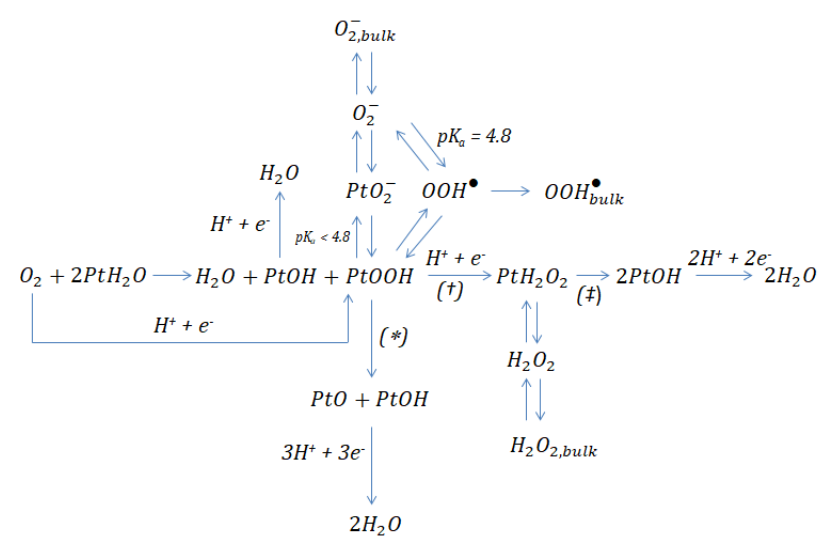

Fig. 4. Proposed scheme mechanism for the ORR on Pt electrodes. (*) Predominant at $2<\mathrm{pH}<3$ and high ionic strength. Unaffected by $\mathrm{Br}_{\text {ads. }}$ This reaction is more favored in $\operatorname{Pt}(100)$ and $\operatorname{Pt}(110)$ than in $\operatorname{Pt}(111)$, and therefore the lifetime of $\mathrm{OOH}^{\bullet}$ is larger on $\mathrm{Pt}(111)$ in acidic media. (†) Favored at very acidic $\mathrm{pH}$ and low ionic strength. ( $\ddagger)$ Hindered in presence of $\mathrm{Br}_{\text {ads. }}$. 
knowledge on the ORR on Pt electrodes have been revised, especially in terms of the effect of the surface charge and the possible mechanism pathways. The electrode surface charge influences the kinetics for the ORR especially in the case of $\mathrm{Pt}(111)$, for which the maximum activity is expected to take place at $\mathrm{pH}=9$. For this $\mathrm{pH}$ value, the pzfc for this surface would be very close to the onset potential for the ORR. The dependence is different for $\operatorname{Pt}(100)$ and $\operatorname{Pt}(110)$ due to the more rigid layer of adsorbed $\mathrm{OH}$ at low potentials, while for stepped surfaces the situation is intermediate. In the case of the HPRR, it was demonstrated that the inhibition that takes place at low potentials on $\mathrm{Pt}(111)$ is directly related to the pme of the surface, and therefore to the pzfc. Recent results point out that the HPRR is sensitive to the local pme of terraces and steps on Pt stepped surfaces.

It can be observed that the behavior of the ORR and the HPRR with $\mathrm{pH}$ is different: while for the HPRR the limiting current density is not affected, the latter decreases as the solution $\mathrm{pH}$ is increased for the ORR. In addition, when both reactions are studied in the presence of $\mathrm{Br}$ - it can be seen that the HPRR is more inhibited than the ORR, especially at neutral $\mathrm{pH}$ values. The solution ionic strength also affects in a different way these reactions. All these results suggest that there exists a bifurcation point in the ORR mechanism prior the formation of $\mathrm{H}_{2} \mathrm{O}_{2}$. This bifurcation point has been proposed to be $\mathrm{OOH}^{\bullet}$ species. This intermediate could exist as a soluble species and it has been demonstrated that it can be formed from an initial chemical step. EC-SHINERS measurements and DFT calculations allowed the identification of the $\mathrm{OOH}^{\bullet}$ intermediate on $\mathrm{Pt}(111)$ in acidic media. This intermediate is more stable in $\operatorname{Pt}(111)$ than in $\mathrm{Pt}(100)$ and $\mathrm{Pt}(110)$ as indicated by the obtained dissociation energies and thus pointing out a surface structure effect.

The fundamental knowledge of the ORR is mandatory in order to develop electrode materials with the better performance from a rational strategy. Theoretical calculations are always carried out using model surfaces. The results derived from them cannot be compared with experiments performed with practical polyoriented surfaces. Direct relationships between the theoretical studies and the experimental measure- ments can only be established when well-oriented surfaces are used, allowing to establish whether calculations are truly representative of the experimental situation. In this sense, the use of Pt single electrodes provides valuable information that can be extrapolated to nanoparticles and therefore to electrocatalysts that can be used in practical applications. Therefore, although the single-crystals electrode cannot be used in practical applications, studies with well-oriented surfaces are important in order to achieve a complete fundamental knowledge of electrocatalytic reactions so that the best practical conditions are stablished. Further experiments with Pt stepped surfaces, which have step sites with a low coordination and a more similar behavior to the less coordinated sites in practical electrodes, and preferentially oriented Pt nanoparticles will be performed in order to obtain more information about how the surface charge affects the ORR and the HPRR and to gain more details about the mechanism of these reactions.

\section{Acknowledgments}

This work was supported by the MINECO-FEDER (project CTQ2016-76221-P). Valentín Briega-Martos thankfully acknowledges to MINECO the award of a predoctoral grant (BES-2014-068176, project CTQ2013-44803-P).

Juan M. Feliu

Instituto de Electroquímica, Universidad de Alicante, Apdo. 99, E-03080 Alicante, Spain

Tel: +34-96-590-9301

Fax: +34-96-590-3537

E-mail: juan.feliu@ua.es

Received 28 June 2019

Published 05 May 2020

DOI: S1872-2067(19)63325-5

\section{References}

[1] A. M. Gómez-Marín, R. Rizo, J. M. Feliu, Catal. Sci. Technol., 2014, 4, 1685-1698.

\section{Graphical Abstract}

Chin. J. Catal., 2020, 41: 732-738 doi: S1872-2067(19)63325-5

Recent progress on oxygen and hydrogen peroxide reduction reactions on Pt single crystal electrodes

Valentín Briega-Martos, Enrique Herrero, Juan M. Feliu * Universidad de Alicante, Spain

The most recent advances for the ORR in Pt single crystal electrodes are summarized. A mechanism for the reaction is presented in light of the recent results.

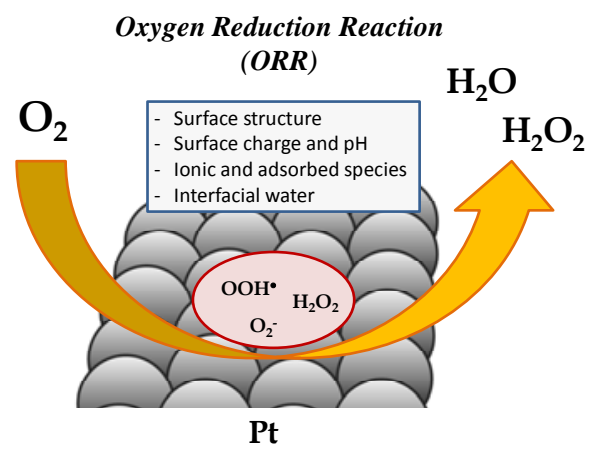


[2] A. Damjanovic, M. A. Genshaw, J. O. M. Bockris, J. Electrochem. Soc., 1967, 114, 466-472.

[3] N. M. Markovic, H. A. Gasteiger, P. N. Ross Jr, J. Phys. Chem., 1995, 99, 3411-3415.

[4] L. Zhang, H. Li, J. Zhang, J. Power Sources, 2014, 255, 242-250.

[5] J. Greeley, J. Rossmeisl, A. Hellman, J. K. Nørskov, Zeitschrift fuer Physikalische Chemie (Muenchen, Germany), 2007, 221, 1209-1220.

[6] M. D. Maciá, J. M. Campina, E. Herrero, J. M. Feliu, J. Electroanal. Chem., 2004, 564, 141-150.

[7] A. Kuzume, E. Herrero, J. M. Feliu, J. Electroanal. Chem., 2007, 599, 333-343.

[8] A. M. Gómez-Marín, J. M. Feliu, Catal. Today, 2015, 244, 172-176.

[9] R. Rizo, E. Sitta, E. Herrero, V. Climent, J. M. Feliu, Electrochim. Acta, 2015, 162, 138-145.

[10] A. M. Gómez-Marín, J. M. Feliu, ChemSusChem, 2013, 6, 1091-1100.

[11] S. Nayak, I. J. McPherson, K. A. Vincent, Angew. Chem. Int. Ed.,
2018, 57, 12855-12858.

[12] J. C. Dong, X. G. Zhang, V. Briega-Martos, X. Jin, J. Yang, S. Chen, Z. L. Yang, D. Y. Wu, J. M. Feliu, C. T. Williams, Z. Q. Tian, J. F. Li, Nat. Energy, 2019, 4, 60-67.

[13] R. Martínez-Hincapié, V. Climent, J. M. Feliu, Curr. Opin. Electrochem., 2019, 14, 16-22.

[14] P. Sebastián, R. Martínez-Hincapié, V. Climent, J. M. Feliu, Electrochim. Acta, 2017, 228, 667-676.

[15] V. Briega-Martos, E. Herrero, J. M. Feliu, Electrochim. Acta, 2017, 241, 497-509.

[16] V. Briega-Martos, E. Herrero, J. M. Feliu, Electrochem. Commun., 2017, 85, 32-35.

[17] N. Garcia-Araez, V. Climent, J. M. Feliu, Electrochim. Acta, 2009, 54, 966-977.

[18] V. Briega-Martos, G. A. B. Mello, R. M. Arán-Ais, V. Climent, E. Herrero, J. M. Feliu, J. Electrochem. Soc., 2018, 165, J3045-J3051.

[19] A. M. Gomez-Marín, J. M. Feliu, E. A. Ticianelli, ACS Catal., 2018, 8, 7931-7943.

[20] J. A. Keith, T. Jacob, Angew. Chem. Int. Ed., 2010, 49, 9521-9525.

\section{Pt单晶电极上氧和过氧化氢还原反应研究进展 \\ Valentín Briega-Martos, Enrique Herrero, Juan M. Feliu * \\ 阿利坎特大学电化学研究所, 阿利坎特, 西班牙}

摘要: 氧还原反应(ORR)可能是电催化中最重要的阴极过程. 尽管最近几年有关ORR反应的实验和理论研究很多, 但ORR 反应完整的机理尚未完全阐述清楚. 本文总结了在单晶Pt电极上ORR反应研究的最新进展, 特别是有关表面电荷的影响和 可能的反应路径, 并基于这些研究结果给出了 ORR反应机理.

关键词: 颈基金纳米簇; 金属氧化物载体; 統基配体; 一氧化碳氧化

收稿日期: 2019-06-28. 接受日期: 2019-08-13. 出版日期: 2020-05-05.

*通讯联系人. 电话: +34-96-590-9301; 传真: +34-96-590-3537; 电子信箱: juan.feliu@ua.es

本文的电子版全文由Elsevier出版社在ScienceDirect上出版(http://www.sciencedirect.com/science/journal/18722067). 